\title{
Epidemiology and serological detection of Rift Valley Fever disease in farm animals in southern Egypt

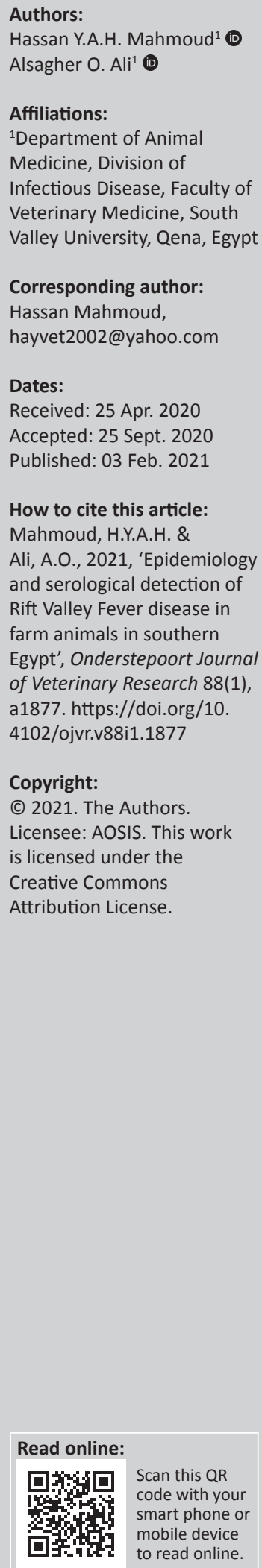

\begin{abstract}
In this study, the serological surveillance of Rift Valley Fever virus (RVFV) in southern Egypt was carried out for 460 serum samples collected from domestic animals (unvaccinated), including cattle, sheep, goat, camel and donkey reared in three different provinces (Qena, Luxor and Aswan). Enzyme linked immunosorbent assay (ELISA) was used to detect RVFV antibodies. The results showed that 97 out of 460 animals were positive by using blocking ELISA. The percentage of RVFV infection in cattle, sheep, goat, camel and donkey was 5.55\%, $65.21 \%, 14.44 \%, 20.65 \%$ and $0 \%$, respectively. Geographical distribution and breeding system were taken into consideration for RVFV infection in these animals. The most prevalent type of infection was identified in intensive breeding farms systems (27.63\%), and then in individual breeding systems (11.68\%). Qena had a higher infection rate of RVFV (23.55\%), in comparison to Aswan and Luxor (20.65\% and $14.14 \%$, respectively). Marked seroprevalence recorded in this study indicates a high incidence of infection in sheep $(65.21 \%)$ and camel $(20.65 \%)$; this necessitates the application of more effective strategies to control these types of infections in Egypt. This study provides a concise picture about the RVFV disease in southern Egypt. We need more similar studies targeted to clarify the reliable epidemiological status of RVFV disease in southern Egypt and other localities.
\end{abstract}

Keywords: farm animals; RVFV; southern Egypt; epidemiology; camel; infectious diseases.

\section{Introduction}

Rift Valley Fever (RVF) is a vector-borne viral disease caused by Rift Valley Fever virus (RVFV), a member of the Bunyaviridae family and Phlebovirus genus that primarily affects domestic ruminants, causing large epizootics with high mortality rates in young animals and abortions in affected dams (Mansfield et al. 2015; Shabani et al. 2015). The virus was discovered in 1930 during an outbreak that affected livestock in East Africa (Daubney \& Hudson 1931; Boushab et al. 2015). Six years later, RVFV antibodies were found in human sera from southern Sudan (Findlay et al. 1936). The primary major human epidemic occurred in 1951 in South Africa (Tolou et al. 2009). Since then, multiple outbreaks were reported in several parts of Africa and the Middle East, notably in Egypt (1977, 2003) (Faye et al. 2007; Sissoko et al. 2009), Kenya (19971998, 2006-2007) (Faye et al. 2010), Saudi Arabia and Yemen (2000-2001) (Al-Hazmi et al. 2003; Nabeth et al. 2001), Sudan $(2007,2010)$ (Hassan et al. 2011; Nabeth et al. 2001), Mayotte (2008) (Sissoko et al. 2009) and Mauritania (1987, 1993-1994, 1998, 2003, 2010, 2012) (Boushab et al. 2015; Faye et al. 2007; Nabeth et al. 2001).

The disease occurrence follows the unusual trend of heavy rainfall leading to flooding, resulting in providing a conducive environment for dormant mosquito eggs infected by RVFV to hatch and become predominant mosquito populations that transmit virus to animals and subsequently from animals to humans (Shabani et al. 2015). However, currently, there is no proof for person-toperson transmission of RVFV (Rakotoarivelo et al. 2011; Shabani et al. 2015). In humans, RVFV infection is typically asymptomatic or causes influenza-like illness accompanied by fever and headache but occasionally leads to serious complications, such as haemorrhagic syndromes, retinitis, encephalitis and death (Adam, Karsany \& Adam 2010; Al-Hazmi et al. 2003; Mansfield et al. 2015; Shabani et al. 2015).

During the late 1980s, a new extension of the geographic range of RVFV into western Africa was detected. In 2000, RVFV caused an epidemic in Saudi Arabia and Yemen, which was the first time that RVFV was detected outside Africa (Balkhy \& Memish 2003; Madani et al. 2003).

Various wildlife species including buffalo and camel have been shown to be seropositive in endemic areas, suggesting a role for these animals in the virus life cycle (Britch et al. 2013). 
Rift Valley Fever virus (RVFV) could also be transmitted to different mosquito species that function as linking vectors to other wild and farm animals and to humans, which can cause more amplification of the transmission cycle (Martin et al. 2008).

Rift Valley fever disease (RVFD) is a vector-borne viral disease of domestic ruminants characterised by widespread abortions and infant deaths, and flu-like symptoms. It is endemic in Egypt, Kingdom of Saudi Arabia and Yemen. Outbreak occurs during periods of high downfall or in the environments supporting the proliferation of RVFV-infected dipteran vectors. RVFV is classified as a category (A) priority infective agent by the National Institute of Allergy and Infectious Diseases, showing the possibility to cause social disturbances and requiring public health awareness. RVFV is the third most dangerous animal threat according to the United States Department of Agriculture Animal and Plant Health Inspection Service. Rift Valley fever virus is a sensible danger that spreads to new geographic areas through the movement of virus-carrying vectors confined within aircrafts and ship cargo holds and the supporting ecological conditions. Vector transmission is poorly understood because of lack of information regarding mosquito ecologies, increasing the risk of entrance of RVFV to a new area.

\section{Materials and methods Animals and geographic locations}

A total of 460 serum samples were collected from apparently and clinically healthy animals, including cattle, sheep, goat, camel and donkey of different age, sex, breeding system and location. Serum samples were collected from animals during the period from May 2017 to June 2019, randomly in different villages in Aswan, Qena and Luxor governorates in southern Egypt (Figure 1), from individual owners and smallholder farms located in a similar environmental and husbandry conditions, characterised by hot and dry weather. In addition, there were 20 sheep that could not be classified as part of the individual or intensive breeding system.

\section{Clinical examination}

Clinical examination was performed for animals physically, including breed, age and sex; body condition, temperature, respiratory rate and mucous membranes were examined and recorded for individual animals in this study.

\section{Blood sampling}

Blood samples were collected through vein puncture from each animal in glass tubes without anticoagulant, and serum was separated by centrifugation and then stored at $-20{ }^{\circ} \mathrm{C}$ until use.

\section{Blocking enzyme-linked immunosorbent assay}

Detection of specific antibodies to the N-protein of RVFV antibodies does not depend on the animal species and can therefore be used with sera samples of all species affected by RVFV, according to the manufacturer's instructions (FVR.K.3/5 Ingezim Rift Valley Fever ${ }^{\mathrm{TM}}$ Compac (Immunologiay Genetica Aplicada S.A, Madrid, Spain).

\section{Technical basis of the test}

The recombinant N-protein of the RVFV was used as the antigen, which is used to bind to a polystyrene plate, and after incubating the sera samples, a RVFV-specific monoclonal antibody (Mab) was added. If the sample contains antibodies specific of the virus, they will not allow the binding of the labelled Mab to the antigen, whereas if it does not contain specific antibodies, the Mab will bind to the antigen, which is coating the plate. By washing the plate to eliminate all non-fixed material, the presence or absence of labelled Mab can be detected by adding the substrate, which, in the presence of the peroxidase, will develop a colorimetric reaction. If there has been colour development, it means that the conjugate has bound to the antigen, and therefore the sample is negative. On the other hand, if the sample contains specific antibodies to RVFV, they will block the binding of the conjugate and there will be no colour development.

\section{Test procedure}

Before starting the test, all reagents should be in room temperature $\left(20{ }^{\circ} \mathrm{C}-25^{\circ} \mathrm{C}\right)$ for $20 \mathrm{~min}$. After that add 80 $\mu \mathrm{L}$ of the diluent fluid to each well and then add $20 \mu \mathrm{L}$ of each sample in every well to be assayed. Add $100 \mu \mathrm{L}$ of positive control (PC) and negative control (NC) to their respective wells, and then seal the plate and incubate for $45 \mathrm{~min}$ at $22{ }^{\circ} \mathrm{C}-25^{\circ} \mathrm{C}$. Wash the plate for four times and then add $100 \mu \mathrm{L}$ of the ready conjugate to each well, and seal the plate and incubate for $30 \mathrm{~min}$ at $22{ }^{\circ} \mathrm{C}-25^{\circ} \mathrm{C}$. Wash the plate for four times and add $100 \mu \mathrm{L}$ of the substrate solution to each well and keep the plate at room temperature for $10 \mathrm{~min}$, and then add $100 \mu \mathrm{L}$ of the stop solution to each well and read the optical density (OD) of each well at $405 \mathrm{~nm}$.

\section{Interpretation of the test}

The test is considered valid when the OD of the NC is higher than 0.8 , and the PC is lower than 0.25. Calculate the inhibition percentage (IP) of each sample as follows: IP of sample $=100-([$ sample OD/NC OD] $\times 100)$, samples will be considered positive when the IP is $\geq 45 \%$, samples will be considered negative when the IP is $\leq 40 \%$, and samples with an IP between $40 \%$ and $45 \%$ should be considered as uncertain.

\section{Ethical consideration}

The study was reviewed and approved by Research Code of Ethics at the South Valley University (RCOE-SVU). 


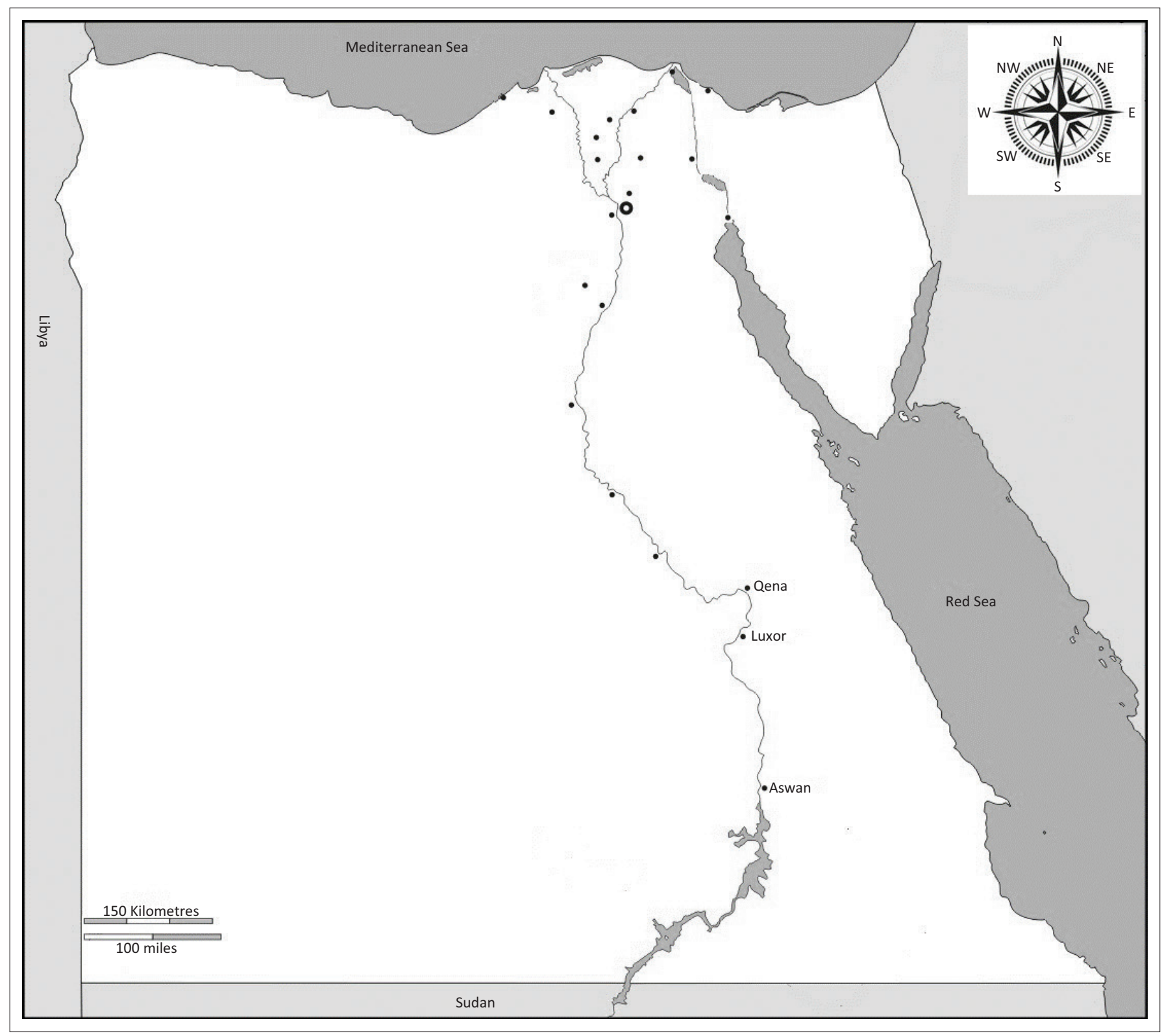

FIGURE 1: Map of Egypt showing the location of Qena, Luxor and Aswan governates, where the samples were collected.

TABLE 1: Classification of animals according to geographical distribution, age, sex and breeding system.

\begin{tabular}{|c|c|c|c|c|c|c|c|}
\hline \multirow{2}{*}{$\begin{array}{l}\text { Type of } \\
\text { animals }\end{array}$} & \multirow{2}{*}{ locations } & \multirow{2}{*}{$\begin{array}{c}\text { Total } \\
\text { number of } \\
\text { animals }\end{array}$} & \multirow{2}{*}{$\begin{array}{c}\text { Age } \\
\text { (years) }\end{array}$} & \multicolumn{2}{|c|}{ Sex } & \multicolumn{2}{|c|}{ Breeding system } \\
\hline & & & & Male & Female & Individual & Intensive \\
\hline Cattle & Qena city & 92 & $1-2$ & 12 & 80 & 12 & 80 \\
\hline Sheep & Qena city & 92 & 6 months -2 & 52 & 40 & 22 & 50 \\
\hline Goat & Luxor city & 92 & $1-2$ & 19 & 73 & 20 & 72 \\
\hline Camels & Aswan city & 92 & $2-3$ & 84 & 8 & 8 & 84 \\
\hline Donkey & Qena city & 92 & $2-3$ & 92 & 0 & 92 & 0 \\
\hline Total & & 460 & - & 259 & 201 & 154 & 286 \\
\hline
\end{tabular}

\section{Result}

Sera samples were collected from 460 animals, including cattle, sheep, goat, camel and donkey in South Egypt from three governorates (Aswan, Luxor and Qena) (Table 1). Investigated sera of animals revealed that the seropositive state of animals against RVFV was $21.08 \%$ (97/460), in overall samples, and, that for each species, cattle, sheep,
TABLE 2: Infection rate of Rift Valley Fever in cattle, sheep, goat, camel and donkey.

\begin{tabular}{lcccccc}
\hline Species & \multicolumn{2}{c}{ Positive } & & \multicolumn{2}{c}{ Negative } & Total \\
\cline { 2 - 3 } & $\boldsymbol{n}$ & $\mathbf{\%}$ & & $\boldsymbol{n}$ & $\mathbf{\%}$ & \\
\hline Cattle & 5 & 5.55 & & 87 & 94.45 & 92 \\
Sheep & 60 & 65.21 & & 32 & 34.79 & 92 \\
Goat & 13 & 14.44 & & 79 & 85.66 & 92 \\
Camel & 19 & 20.65 & & 73 & 79.35 & 92 \\
Donkey & 0 & 0.00 & & 92 & 100.00 & 92 \\
\hline Total & $\mathbf{9 7}$ & $\mathbf{2 1 . 0 8}$ & & $\mathbf{3 6 3}$ & $\mathbf{7 9 . 9 2}$ & $\mathbf{4 6 0}$ \\
\hline & & & & & &
\end{tabular}

goat, camel and donkey were 5.55\% (5/92), 65.21\% (60/92), $14.44 \%(13 / 92)$ and $0 \%(0 / 92)$, respectively (Table 2$)$. Epidemiological status was established to clarify the influence of age, sex, location and management system (individual/intensive farming system). It revealed that Qena had a higher infection rate $(23.55 \%)$ than Aswan and Luxor, $20.65 \%$ and $14.14 \%$, respectively (Table 3). Marked infection was recorded in sheep $(65.21 \%)$ and camels 
TABLE 3: Rift Valley Fever infection in animals regard to location, age, sex and breeding system.

\begin{tabular}{|c|c|c|c|c|c|c|c|c|c|c|c|c|c|c|c|c|c|c|c|c|}
\hline \multirow[t]{3}{*}{ Factors } & \multicolumn{6}{|c|}{ Location } & \multicolumn{6}{|c|}{ Age } & \multicolumn{4}{|c|}{ Sex } & \multicolumn{4}{|c|}{ Breeding system } \\
\hline & \multicolumn{2}{|c|}{ Aswan } & \multicolumn{2}{|c|}{ Luxor } & \multicolumn{2}{|c|}{ Qena } & \multicolumn{2}{|c|}{$\begin{array}{c}6 \text { months- } \\
1 \text { year }\end{array}$} & \multicolumn{2}{|c|}{$1-2$ years } & \multicolumn{2}{|c|}{$2-3$ years } & \multicolumn{2}{|c|}{ Male } & \multicolumn{2}{|c|}{ Female } & \multicolumn{2}{|c|}{ Individual } & \multicolumn{2}{|c|}{ Intensive } \\
\hline & $n$ & $\%$ & $n$ & $\%$ & $n$ & $\%$ & $n$ & $\%$ & $n$ & $\%$ & $n$ & $\%$ & $n$ & $\%$ & $n$ & $\%$ & $n$ & $\%$ & $n$ & $\%$ \\
\hline $\begin{array}{l}\text { Positive number } \\
\text { of tested animals }\end{array}$ & 19 & 20.65 & 13 & 14.14 & 65 & 23.55 & 50 & 54.35 & 73 & 39.67 & 19 & 10.32 & 60 & 23.17 & 37 & 18.41 & 18 & 11.68 & 79 & 27.63 \\
\hline $\begin{array}{l}\text { Negative number } \\
\text { of tested animals }\end{array}$ & 73 & 79.35 & 79 & 86.86 & 211 & 76.45 & 42 & 45.65 & 111 & 60.33 & 165 & 89.68 & 199 & 76.83 & 164 & 81.59 & 136 & 88.32 & 207 & 72.37 \\
\hline $\begin{array}{l}\text { Total number of } \\
\text { tested animals }\end{array}$ & 92 & - & 92 & - & 276 & - & 92 & - & 184 & - & 184 & - & 259 & - & 201 & - & 154 & - & 286 & - \\
\hline
\end{tabular}

$(20.65 \%)$, more than goats $(14.44 \%)$, cattle $(5.55 \%)$ and donkeys $(0.0 \%)$.

\section{Data management and analysis}

The data was collected and analysed using Microsoft 2016 Excel (http://www.microsoft.com/en-eg/download/ details.aspx?id=50283)

\section{Discussion}

Arboviruses are one amongst the re-emerging pathogens that recently produce unhealthiness everywhere. One-hundred and fifty arboviruses are documented to cause sickness in humans, and the majority is animal diseases, supported by exceeding transmission cycle between arthropods as vectors and vertebrate creature reservoirs as the main amplifying hosts. RVFV is one amongst the foremost aggressive migrating arboviruses. It is transmitted in an enzootic cycle amongst wildlife and mosquitoes, besides wild and farm animals (Figueiredo 2007).

Camel is believed to be resistant to RVFV under clinical conditions, with no apparent infection (Swanepoel \& Coetzer 2004). However, clinical signs together with fever and abortion in approximately $10 \%$ of pregnant shecamels were determined in free-ranging herds during the 2006-2007 outbreak in Kenya (Munyua et al. 2010). Proof of RVFV circulation amongst domestic camels has also been reported (Munyua et al. 2010; Nabeth et al. 2001; Olaleye, Tomori \& Schmitz 1996). The current study revealed that the seroprevalence of RVFV in camels was $21.11 \%$; this result is considered as a high percentage of seropositivity, indicating camels act as reservoir for maintenance of RVFV and high precautions should be applied as camels are used in Egypt for meat and milk production and in Aswan and Luxor for entertainment. The routes of spreading detected to date appear to be in parallel with the migration routes of camels. Therefore, there is some smart proof that viremic, non-symptomatic infected camels transported the virus to Egypt and probably conjointly to the peninsula (Hoogstraal et al. 1979).

Horses appear to be resistant to RVFV (Swanepoel \& Coetzer 2004), and experimental infections didn't result in symptoms or viremia (Daubney \& Hudson 1931). However, within the lower Nile River, RVFV antibodies are detected in horses and donkeys (Eisa 1984; Meegan, Hoogstraal \& Moussa 1979).
Moreover, in Nigeria, RVFV antibodies were detected in horses using a complement fixation test (Olaleye et al. 1989; Olaleye et al. 1996), and the virus was isolated in Nigeria from sheep around 1959; however, this wasn't related to an epizootic event (Adeyeye, Ekong \& Pilau 2011), and serological results in this time that were obtained from zebras (Equus burchelli) were negative. This result may clarify that equine might not support RVFV. In this study, the seroprevalence of RVFV in donkey was $0 \%$, indicating that donkeys in Egypt do not maintain RVFV. The result from the examination of cattle, sheep and goat sera revealed that 5 $(5.55 \%), 60(65.21 \%)$ and $13(14.44 \%)$, respectively, were seropositive for RVFV. According to the geographical distribution, Qena had a higher prevalence of RVFV (23.55\%) than Aswan (20.65\%) and Luxor (14.14\%). In regard to the breeding system, there is a higher prevalence of seropositivity in intensive breeding system (27.63\%) than individual breeding system $(11.68 \%)$. The result for farm animals in the southern part of Egypt leads us to indicate that there is no risk factor either from the breeding system or geographic location in the southern part of Egypt. This may be because there is no high difference in temperature and climate in this area.

The geographic distribution of RVF has changed widely from its discovery in 1931 (Daubney \& Hudson 1931). Rift Valley Fever disease started in Eastern Africa, then it emerged throughout Africa as well as to Madagascar and the southern part of Egypt. The first step in the control of RVFV disease is early detection of the disease in animals by applying active police roles for investigation and herd monitoring (Davies \& Martin 2006). In addition, there is transovarian transmission in arthropod and it is a crucial mechanism for the persistence of RVFV in endemic areas (Linthicum et al. 1988). But transovarian transmission alone is not enough to control of RVFV endemicity over long periods. It should be investigation of different host, including wild animals and domestic mammals, between the large-scale of outbreak.

\section{Conclusion}

This study provides valuable data on the high prevalence of RVFV in sheep and camel in southern Egypt; this will assist in the development of prevention and control strategies for the disease. The high prevalence of RVFV antibodies in camel might be the principal factor limiting the livestock industry in Egypt. More research and effort are needed from governmental and non-governmental authorities to minimise 
the economic losses caused by RVFV, in addition to the zoonotic risks from RVFV infections.

\section{Acknowledgements Competing interests}

The authors declare that they have no financial or personal relationships that may have inappropriately influenced them in writing this article.

\section{Authors' contributions}

Both authors contributed equally to this work.

\section{Funding information}

The authors appreciate the financial support by South Valley University, Higher Education, and Scientific Research Sector.

\section{Data availability statement}

Data sharing is not applicable to this article as no new data were created in this study.

\section{Disclaimer}

The views and opinions expressed in this article are those of the authors and do not necessarily reflect the official policy or position of any affiliated agency of the authors.

\section{References}

Adam, A.A., Karsany, M.S. \& Adam, I., 2010, 'Manifestations of severe Rift Valley Fever in Sudan', The International Journal of Infectious Diseases 14(2), e179-e180. https://doi.org/10.1016/j.ijid.2009.03.029

Adeyeye, A.A., Ekong, P.S. \& Pilau, N.N., 2011, 'Rift Valley fever: The Nigerian story', Veterinaria Italiana 47(1), 35-40.

Al-Hazmi, M., Ayoola, E.A., Abdurahman, M., Banzal, S., Ashraf, J., El-Bushra, A. et al., 2003, 'Epidemic Rift Valley Fever in Saudi Arabia: A clinical study of severe illness in humans', Clinical Infectious Diseases 36(3), 245-252. https://doi. in humans', Clinical

Balkhy, H.H. \& Memish, Z.A., 2003, 'Rift Valley Fever: An uninvited zoonosis in the Arabian Peninsula', International Journal of Antimicrobial Agents 21(2), 153-157. https://doi.org/10.1016/S0924-8579(02)00295-9

Boushab, B.M., Savadogo, M., Sow, S.M. \& Soufiane, S., 2015, 'Survey of investigation around cases of Rift Valley Fever at Tagant, Mauritania', Revue d Épidémiologie e de Santé Publique 63(3), 213-216. https://doi.org/10.1016/j.respe.2015.03.124

Britch, S.C., Binepal, Y.S., Ruder, M.G., Kariithi, H.M., Linthicum, K.J., Anyamba, A. et al., 2013, 'Rift Valley Fever risk map model and seroprevalence in selected wild ungulates and camels from Kenya', PLoS One 8(6), e66626. https://doi. org/10.1371/journal.pone.0066626

Daubney, R. \& Hudson, J.R., 1931, 'Enzootic hepatitis or Rift Valley Fever: An undescribed virus disease of sheep, cattle, and man from east Africa', The Journa of Pathology and Bacteriology 34(4), 545-579. https://doi.org/10.1002/path. 1700340418

Daubney, R. \& Hudson, J.R., 1932, 'Rift Valley Fever', The Lancet 219(5664), 611-612. https://doi.org/10.1016/S0140-6736(01)24634-0
Davies, F.G. \& Martin, V., 2006, 'Recognizing Rift Valley Fever', Veterinaria Italiana 42(1), 31-53.

Eisa, M., 1984, 'Preliminary survey of domestic animals of the Sudan for precipitating antibodies to Rift Valley Fever virus', Journal of Hygiene 93(3), 629-637. https:// doi.org/10.1017/S0022172400065207

Faye, O., Ba, H., Ba, Y., Freire, C.C., Faye, O., Ndiaye, O. et al., 2010, 'Reemergence of Rift Valley Fever, Mauritania, 2010', Emerging Infectious Diseases Journal 20(2), 300-303. https://doi.org/10.3201/eid2002.130996

Faye, O., Diallo, M., Diop, D.O., Bezeid, E., Bâ, J., Niang, M. et al., 2007, 'Rift Valley Fever outbreak with East-Central African virus lineage in Mauritania', Emerging Infectious Diseases Journal 13(7), 1016-1023. https://doi.org/10.3201/ eid1307.061487

Figueiredo, L.T., 2007, 'Emergent arboviruses in Brazil', Revista da Sociedade Brasileira de Medicina Tropical 40(2), 224-229. https://doi.org/10.1590/S0037 de Medicina Tropical
86822007000200016

Findlay, G.J., Stefanopoulo, G.M. \& Mac Callum F., 1936, ‘Présence d’anticorps contre la fièvre de la vallée du Rift dans le sang des africains', Bulletin de la Société de Pathologie Exotique 29, 986-996.

Hassan, O.A., Ahlm, C., Sang, R. \& Evander, M., 2011, 'The 2007 Rift Valley Fever outbreak in Sudan', PLOS Neglected Tropical Diseases 5(9), e1229. https://doi. org/10.1371/journal.pntd.0001229

Hoogstraal, H., Meegan, J.M., Khalil, G.M. \& Adham, F.K., 1979, 'The Rift Valley Fever epizootic in Egypt 1977-78. 2. Ecological and entomological studies', Transactions of The Royal Society of Tropical Medicine and Hygene 73(6), 624-629. https://doi. org/10.1016/0035-9203(79)90005-1

Linthicum, K.J.L., Bailey, C.L., Davies, F.G., Kairo, A. \& Logan, T.M., 1988 ' The horizontal distribution of Aedes pupae and their subsequent adults within a flooded dambo in Kenya: Implications for Rift Valley Fever virus control', Journal of the American in Kenya: Implications for Rift Valley Fever vito Control Association 4(4), 551-554.

Madani, T.A.L., Al-Mazrou, Y.Y., Al-Jeffri, M.H., Mishkhas, A.A., Al-Rabeah, A.M., Turkistani, A.M. et al., 2003, 'Rift Valley Fever epidemic in Saudi Arabia: Epidemiological, clinica and laboratoy characterisitics', Clinical Infectious Diseases 37(8), 1084-1092. https://doi.org/10.1086/378747

Mansfield, K.L., Banyard, A.C., McElhinney, L., Johnson, N., Horton, D.L., HernándezTriana, L.M. et al., 2015, 'Rift Valley Fever virus: A review of diagnosis and vaccination, and implications for emergence in Europe', Vaccine 33(42) 5520-5531. https://doi.org/10.1016/j.vaccine.2015.08.020

Martin, V.L., Chevalier, V., Ceccato, P., Anyamba, A., De Simone, L., Lubroth, J. et al., 2008 , 'The impact of climate change on the epidemiology and control of rift Valley Fever', Revue scientifique et technique (International Office of Epizootics) 27(2), 413-426. https://doi.org/10.20506/rst.27.2.1802

Meegan, J.M., Hoogstraal, H. \& Moussa, M.I., 1979, 'An epizootic of Rift Valley Fever in Egypt in 1977', Veterinary Record 105(6), 124-125. https://doi.org/10.1136/ vr.105.6.124

Munyua, P., Murithi, R.M., Wainwright, S., Githinji, J., Hightower, A., Mutonga, D. et al., 2010, 'Rift Valley Fever outbreak in livestock in Kenya, 2006-2007', American et al., 2010, 'Rift Valley Fever outbreak in livestock in Kenya, 2006-2007', American
Journal of Tropical Medicine and Hygiene 83(2), 58-64. https://doi.org/10.4269/ ajtmh.2010.09-0292

Nabeth, P., Kane, Y., Abdalahi, M.O., Diallo, M., Ndiaye, K., Ba, K. et al., 2001, 'Rift Valley Fever outbreak, Mauritania, 1998: Seroepidemiologic, virologic, entomologic, and zoologic investigations', Emerging Infectious Diseases 7(6), 1052-1054. https://doi.org/10.3201/eid0706.010627

Olaleye, O.D., Oladosu, L.A., Omilabu, S.A., Baba, S.S. \& Fagbami, A.H., 1989, 'Complement fixing antibodies against arboviruses in horses at Lagos, Nigeria', Revue d'Elevage et Médecine Vétérinaire des Pays Tropicaux 42(3), 321-325.

Olaleye, O., Tomori, O. \& Schmitz, H., 1996, 'Rift Valley Fever in Nigeria: Infections in domestic animals', Revue Scientifique et Technique 15(3), 937-946. https://doi. org/10.20506/rst.15.3.966

Rakotoarivelo, R.A., Andrianasolo, R., Razafimahefa, S.H., Randremandranto Razafimbelo, N.S. \& Randria, M.J., 2011, 'Severe presentations of Rift Valley Fever in Madagascar', Médecine et Maladies Infectieuses 41(6), 318-321. https://doi. org/10.1016/j.medmal.2010.12.007

Shabani, S.S., Ezekiel, M.J., Mohamed, M. \& Moshiro, C.S., 2015, 'Knowledge, attitudes and practices on Rift Valley Fever among agro pastoral communities in Kongwa and Kilombero districts, Tanzania', BMC Infectious Diseases 15(1), 363. https://doi.org/10.1186/s12879-015-1099-1

Sissoko, D., Giry, C., Gabrie, P., Tarantola, A., Pettinelli, F., Collet, L. et al., 2009, 'Rift Valley Fever, Mayotte, 2007-2008', Emerging Infectious Diseases 15(4), 568-570. https://doi.org/10.3201/eid1504.081045

Swanepoel, R. \& Coetzer, J.A.W., 2004, 'Rift Valley Fever', in J.A.W. Coetzer, G.R. Thomson \& R.C. Tustin (eds.), Infectious diseases of livestock, pp. 1037-1070, Oxford University Press, Oxford. 